\title{
Bajo el signo de Kandinsky. Sobre el devenir puro de las poéticas de los hermanos Maldonado Bayley*
}

Fecha de recepción: 6 de febrero de 2018

Fecha de aprobación: 04 de mayo de 2018

\section{Resumen}

La obra de Tomás Maldonado (1922), pintor y diseñador, la de Edgar Bayley (1919-1990), poeta; comparten los rasgos de simplicidad, sobriedad y exactitud. Pero su lazo familiar, no resulta suficiente para explicar ese "aire de familia" que emparenta sus producciones. La diferencia de las disciplinas hace que esos rasgos se tornen difusos para compararlas. A partir de la problematización del concepto de «pureza de las formas», que atraviesa el desarrollo del arte abstracto y de la poesía moderna, y del análisis comparativo de las producciones teóricas de ambos, este trabajo busca indagar acerca de las influencias mutuas y las reflexiones conjuntas, que los llevaron a coincidir y a elaborar una discursividad vanguardista consolidada, que terminó por hermanar sus producciones.

Palabras clave: Tomás Maldonado; Edgar Bayley; pureza de las formas; vanguardia; arte concreto; diseño; invencionimo.

Citar: Del Gizzo, L. (enero-junio de 2018). Bajo el signo de Kandinsky. Sobre el devenir puro de las poéticas de los hermanos Maldonado Bayley. La Palabra,(32), 65-84. doi.org/10.19053/01218530.n32.2018.8164.

\section{Luciana Del Gizzo}

Doctora en Literatura, Universidad de Buenos Aires. Fue becaria doctoral y posdoctoral del Consejo Nacional de Investigaciones Científicas y Técnicas (Conicet). Docente de la Facultad de Filosofía y Letras, Universidad de Buenos Aires, Argentina.

violeta07@gmail.com

*Artículo de investigación 


\section{la palabra}

\section{Under the Sign of Kandinsky. On Pure Becoming in the Poetics of the Maldonado Bailey Brothers}

\section{Abstract}

The work of Tomás Maldonado (1922), painter and designer, and Edgar Bayley (1919-1990), poet, share the features of simplicity, sobriety, and accuracy. But their blood relation is not enough to explain that "family air" that binds their productions. Their different artistic disciplines blurs the comparison of these features in their work. This study starts from the concept of «purity of forms», present in the development of abstract art and modern poetry, and the comparative analysis of the theoretical productions of both artists, and inquires about mutual influences and joint reflections which led them to agree on and elaborate a consolidated avant-garde discourse, which ended up linking their productions.

Key Words: Tomás Maldonado; Edgar Bayley; Purity of form; Avant-garde; Concrete art; Design; Inventionism.

\section{Sous le signe de Kandinsky. Sur le devenir simple des poétiques des frères Maldonado Bayley}

\section{Résumé}

Le travail du peintre et designer Tomás Maldonado (1922) partage des caractéristiques de simplicité, de dépouillemet et de précision avec celui du poète Edgar Bayley (1919-1990). Mais lien lien familial n'explique pas cet «air de famille» que partagent leurs productions. En plus, la différence des disciplines qu'ils pratiquent, rend les traits vagues pour les comparer. Nous analyserons de quelle manière à partir des influences réciproques et des réflexions communes ils se sont mis d'accord et ont construit une discursivité d'avant-garde consolidée, qui a fini par rapprocher leurs productions. On utilisera, pour mener à terme notre projet, la problématisation du concept de «pureté des formes», qui traverse le développement de l'art abstrait et de la poésie moderne. On réalisera une analyse comparative des productions théoriques des deux frères.

Mots-clés: Tomás Maldonado; Edgar Bayley; pureté des formes; avant-garde; art concret; design; invencionismo. 
"Una extrema simplicidad, una reducción a lo esencial. [...] Pocos componentes métricamente coordinados". Los atributos que utiliza Gui Bonsiepe, ${ }^{1}$ para analizar el diseño de un juego de tazas y teteras expuesto en la exposición itinerante «Modelos de Ulm, el diseño de la nueva Alemania/1953-1968», que pasó por el Museo Nacional de Bellas Artes de Argentina en 2008, bien podrían aplicarse a la poesía de Edgar Bayley de la misma época. Incluso, la descripción sería exacta si no fuera porque señala que los objetos son «arquetipos del modelo ulmiano», «métodos matemáticos generativos de la forma» -o tal vez lo sea si interpretamos la metáfora-. ${ }^{2}$ ¿Pero hasta qué punto resulta lógico vincular una poética originada en América del Sur con el diseño moderno de objetos producido en Europa después de la Segunda Guerra Mundial y las experimentaciones de la vanguardia constructivista?

La relación es menos caprichosa de lo que parece: Tomás Maldonado, hermano de Bayley, no solo fue profesor de la Hochschule für Gestaltung (HfG) en Ulm, Alemania, desde 1954, sino que desempeñó cargos decisivos hasta convertirse en su rector diez años después. El argentino tuvo una parte importante en el desarrollo del diseño alemán de la época, pero esto no garantiza que haya influenciado la producción poética de su hermano, sobre todo, porque su desempeño en Europa implicó la separación física y la disolución del intercambio intelectual de juventud. Sin embargo, un hilo conecta la producción madura de ambos bajo los rasgos comunes de simplicidad, economía de recursos y pureza de las formas. Entonces, ¿qué es lo que realmente subyace a este «aire de familia» en sus obras? ¿Qué produjo esa similitud entre producciones de disciplinas diversas?

El lazo de sangre no brinda una respuesta a estas preguntas. La relación personal, aunque amorosa y de respeto mutuo, no pudo evadir ni la rivalidad natural que caracteriza los vínculos de hermanos ni la voluntad de diferenciarse, de marcar un territorio propio de influencia, ejemplificados por el cambio del apellido en Bayley y la elección de disciplinas afines pero contrapuestas. ${ }^{3}$ Igualmente, los intercambios determinaron muchas de las decisiones que delinearon sus poéticas. Más que la consanguineidad, aquello que proporcionó esa similitud en sus poéticas fueron las búsquedas conjuntas en la juventud y las posteriores influencias mutuas, ya fueran directas en los intercambios o indirectas en la reflexión de la labor del otro.

Entonces, ¿de dónde provenía exactamente esa simplicidad, esa pureza de las formas? Un interés compartido por las expresiones vanguardistas menos difundidas en Argentina, que provenían de Rusia y sus elaboraciones en Alemania, Holanda o Suiza, los llevó en su juventud a hurgar en amarillentos papeles que habían cruzado el Atlántico junto con los inmigrantes judíos, alemanes, checos, españoles, etc.: antes de cumplir los 20 años de edad habían armado una red de información sobre el constructivismo, el neoplasticismo, la Bauhaus, el cubismo y el arte abstracto en general. El procesamiento de ese modernismo los llevaría a plantear una poética más que antimimética, contra la representación, como un camino para despojar al arte de todo lo que fuera accesorio a su esencia.

La pureza de las formas que proponen esos movimientos, no implica lo mismo para las artes visuales que para la poesía y, de

1 Gui Bonsiepe (Alemania, 1934). Diseñador industrial, teórico y docente de la HfG de Ulm, fue junto a Tomás Maldonado la mayor influencia sobre la disciplina en Argentina.

2 El testimonio está recogido del documental «Composición, de Tomás Maldonado», Film\&Arts. Disponible en: https://www. youtube.com/watch?v=lo-q1lyftEl

3 El vínculo filial de los hermanos Maldonado Bayley fue ya analizada en relación con las tensiones e influencias de las disciplinas afines a las que se dedicaron en Del Gizzo, Luciana. 2017. «Irish Temper. Acerca de la relación artística y personal de los hermanos Maldonado Bayley». Landa, vol. 5 (2), 426-448. Disponible: http://www.revistalanda.ufsc.br/vol-5-n2-2017/ 
hecho, el concepto proviene de distintas tradiciones, de acuerdo con la disciplina, por lo que también conduce a diferentes conceptualizaciones y prácticas. Mientras en la literatura moderna, la noción de «poesía pura» puede rastrearse hasta Mallarmé, sin omitir sus antecedentes en Flaubert y Rimbaud, y en artes visuales el hito lo constituye Malévitch con su cuadrado blanco sobre blanco, el derrotero y el resultado posterior de ambos conceptos difícilmente es homologable en ambas disciplinas. Entonces, ¿es posible pensar en «la pureza de las formas» como un concepto que emparenta las obras de los hermanos Maldonado-Bayley? A partir de esta pregunta, este trabajo busca indagar acerca de las influencias mutuas entre estos artistas, que los llevaron a coincidir en ciertos rasgos estilísticos que terminaron por hermanarlos.

\section{Palabras y colores que son co-} sas

En Las palabras y las cosas, Foucault (2002) fecha un momento de discontinuidad entre las palabras y aquello que representan a fines del siglo XVI, cuando el signo cambia su carácter y su relación con lo real: el lenguaje ya no es la signatura de las cosas, sino que actúa como la mediación que traduce, en la medida de sus posibilidades, la verdad manifestada en lo real. Se trata del momento en que el arte se vuelve autoconsciente y recursivo sobre su propio mecanismo de significación, tematizando la representación en sus obras, gracias a que advierte la distancia entre su especificidad y la realidad que reproduce.

La separación entre semejanza y afirmación, es la norma que determina la relación del arte y lo real desde el siglo XVII hasta las vanguardias, cuando se produce un nuevo quiebre epistémico al problematizar ese estatuto del signo: pretendieron deshacer la distancia entre las palabras y las cosas cuestionando el carácter mediador del lenguaje, es decir, destruyendo la similitud de la representación para otorgarle entidad propia a sus producciones. Las vanguardias suponen entonces un nuevo momento de discontinuidad por dos vías: por un lado, al romper con la disyunción entre el código visual y el lingüístico, explotan la tensión entre ambos y ponen en primer plano al signo como el enlace entre los dos códigos -típicamente, la operación de Magritte que analiza Foucault (2012)-; por otro, al rechazar la representación mediante las múltiples formas abstractas, reclaman una nueva relación del arte con lo real, es decir, un nuevo estatuto para el signo artístico, entendido hasta ese momento como el enlace entre la imagen y el discurso.
A partir de allí, el signo artístico vanguardista no sería la medida de otra cosa, sino una presencia en sí misma, que ejerce sentido por su interacción directa con lo real. Hasta el siglo XX,

[...] no se pueden disociar semejanza y afirmación. La ruptura de este principio se puede colocar bajo el signo de Kandinsky: doble borramiento simultáneo de la semejanza y del vínculo representativo mediante la afirmación cada vez más insistente de esas líneas, de esos colores de los cuales Kandisnky decía que eran 'cosas' (Foucault, 2012, p. 31).

Durante la fase final del expresionismo, que había procurado correr el foco de la pintura desde el objeto a la subjetividad del artista, Kandinsky llevó más allá este concepto hasta llegar a la pintura no-objetiva, es decir, aquella que prescinde completamente de la representación de un objeto y se funda en sus elementos básicos -líneas, colores, leyes de composiciónpara evocar emociones o, en sus términos, generar vibraciones interiores. El signo artístico es entonces para el abstraccionismo objeto en sí, en tanto religa los códigos en una unidad basada en sus componentes intrínsecos sin elementos externos, en su pureza.

Renato Poggioli (1964) ubica más atrás, en Mallarmé, el nacimiento del ideal de la poesía 
pura $^{4}$; y en Cèzanne, el de una pintura y una escultura puras, lo que resulta lógico si se piensa en la exaltación del aspecto sígnico del arte tanto en el simbolismo como en elimpresionismo. En ambos, el objeto representado dejó de ser el único fin y dio lugar a la atención sobre los medios materiales, un paso previo a la inobjetividad. Ahora bien, el hecho de que ambas disciplinas compartieran el ideal en momentos contemporáneos no las hermana en el intento de realizarlo. Si el primero descubre "la poesía que surge del espíritu irracional y no conceptual del lenguaje, que se opone a toda interpretación lógica" (Hauser, 1964, p. 430) y hace vibrar el sentido de una idea por fuera de su materialidad; el segundo, en cambio, asienta sobre el material pictórico la percepción subjetiva de la realidad. La diferencia radica, justamente, en el lugar otorgado a sus medios expresivos.

Por eso, la reducción de cada disciplina a sus elementos puros implicaría el repliegue de cada una a sus propios elementos, dado que, como dice Malraux, "exigir de la pintura y de la poesía el primado de sus medios de expresión significa exigir una poesía más poesía y una pintura más pintura, es decir, menos poesía" (Poggioli, 1964, p. 208). También, menos realidad exterior, porque «la pureza del arte había sido concebida en función del concepto retórico de hipérbole, en el sentido de una tensión verbal y formal que acentuase la distinción entre la inmaculada artificialidad de la creación artística y la impura naturalidad de lo real» (p. 209). En ese repliegue sobre el artificio, en contraposición con lo real, Poggioli propone un paralelismo interesante:

[...] parece ahora evidente la analogía que existe entre la función que ha ejercido en la poesía la palabra-metáfora, la palabra-símbolo, la palabra-idea, y la que han ejercido en el campo figurativo líneas y planos, masas y volúmenes, manchas y colores: en otros términos, un estilo plástico que no confíe ya en las sugestiones de la sombra y de la luz, sino en la severa belleza de la forma contemplada en el espacio eterno y absoluto. Mediante estos procedimientos, que revelan una nueva visión más que una nueva técnica, las artes figurativas parecen tender a la creación de una realidad aislada y autónoma, generada por partenogénesis, sin mezcla con la realidad circunstante (Poggioli, 1964, p. 210).

La correspondencia permite advertir la tendencia de ambos a crear una realidad propia, un mundo autónomo con códigos y sentidos propios. Si el arte no podía terminar de desocultar la verdad escondida en el objeto representado, le quedaba exponer sus propios materiales como la única certeza que le cabía. El objetivo era parejo tanto para la poesía como para la pintura: la subversión de la inobjetividad no radicaba únicamente en su negación a la representación o a decir algo sobre lo real, sino fundamentalmente en una expresión que se resistía a colocarse donde la noción burguesa de arte procuraba ponerlo y a develar una pretendida verdad por debajo de lo aparente. Este tipo de analogías entre lenguajes artísticos que se reducen a sus estructuras, supone la "ilusión de la traductibilidad o de la correspondencia recíproca de las artes" (Poggioli, 1964, p. 145), que es la base de la experimentación, cuyo fin último es el de «ensanchar los límites de

\footnotetext{
$4 \quad$ Ver también Bejarano (2016) para un estudio sobre la transformación del rol de poeta a partir de Mallarmé y su repercusión en la teoría literaria de Jacques Ranciere.

5 Como Poggioli, Malraux ubica en el impresionismo la primera reducción de la pintura hacia sus medios expresivos, un antecedente del camino hacia la no representación que abre Kandinsky, pero analiza en la obra de Manet ese giro de la mirada del artista: señala que en el Bar al Folies-Bergère la "materia es una materia pictórica, no representada. El cuadro se convierte en superficie" (1956, p. 114-115).
} 
un arte o de invadir el terreno del otro» (p. 144). ${ }^{6}$

Ahora bien, la traductibilidad de los lenguajes artísticos es únicamente discursiva o reflexiva, en la medida que la pintura sigue siendo pintura; y la poesía, poesía -incluso en los caligramas, que son torpemente visuales-. Esto es así no solo por el ideal de pureza, que no prevalece en todas las vanguardias, sino fundamentalmente por la consumada disociación entre la semejanza que supone la imagen y la afirmación que conlleva el lenguaje (Foucault, 2012), la enorme distancia entre lo dicho y lo visto. ${ }^{7}$ Por eso, el ideal de pureza era para ambas disciplinas un giro hacia sus propios medios de expresión y, por eso, una puerta de entrada a la abstracción, que prescinde del objeto y se repliega a trabajar con sus propias estructuras: en plástica, con los elementos geométricos y las leyes de la composición; en poesía, con el carácter sígnico de la palabra, pero también con la estructura del lenguaje, la gramática. Es decir, se dejan de lado los factores que generan sentido por fuera de la obra misma, incluida la vibración espiritual que buscaba Kandinsky. ${ }^{8}$

En efecto, incluso la expresión de la subjetividad del artista era un elemento heterónomo que contaminaba el arte puro. Para Malévich, que había sido influenciado por el impresionismo y cuyo suprematismo implicó el final del mundo representativo, el objeto era un lastre que impedía liberarlo, por lo que rechazaba cualquier tipo de sentido para dar lugar a la pura superficialidad de la materia y el color. ${ }^{9}$ En la misma línea, sus amigos poetas, Alekséi Kruchónyj y Velimir Jlébnikov, escribían en záum, una experimentación lingüística que trabajaba con el plano fónico, aboliendo el sentido como el elemento del lenguaje que determina la representación. Esto se encontraba en las antípodas del simbolismo: en este, la palabra cobraba un plus de sentido, dado que se explotaba su carácter simbólico indivisible y la significación que se producía en la relación activa entre la idea y la materialidad fónica y escrita, haciendo del hiato entre una y otra el hueco donde se revela lo inefable; las experimentaciones de los futuristas rusos, en cambio, buscaban desarmar la relación, más aún, abolirla, dejando fuera el referente, centrándose en la pura superficie fónica.

Entonces, el nivel más absoluto y esencial de estos lenguajes es la superficie misma de su materialidad. «Pasión por lo real» llama Badiou a la intención que tuvo el pensamiento del siglo XX de develar una verdad corroborada en los hechos y en esa búsqueda no dudó en hacer trizas los velos que ocultaban la supuesta certeza: "[...] una vigorosa corriente de pensamiento afirmó que era mejor sacrificar el arte que ceder en cuanto a lo real. Podemos denominar

$6 \quad$ Apollinaire fue probablemente el primero en advertir esa potencia del vínculo disciplinario y de hecho su obra contiene todas las posibilidades de la vanguardia poética en ciernes. Allí está la simultaneidad poética, visual y rítmica, un collage de elementos disímiles, una adición de sentidos superpuestos; y también el juego con el sinsentido, la ruptura de la lógica del lenguaje, en la línea de quitarle los elementos accesorios de la representación. Pero, todavía en su poética persisten las imágenes, la expresión del yo, la anécdota, que contaminan la pureza.

7 Esta misma cuestión podría ser un argumento viable para explicar la disgregación que, a menudo, ocurre en las vanguardias entre teoría y práctica, esto es, los postulados expresados en los manifiestos y su ejercicio en la producción artística. En la medida en que el lazo entre semejanza y afirmación no puede ya reconstruirse, la teoría, como descripción de una práctica, no puede afirmar la relación que el arte ejerce con lo real, que de todas formas en la vanguardia ya no es de semejanza. No obstante, hay que considerar también el avance posterior del discurso en el arte, que alcanza su punto máximo en el arte conceptual.

8 Esta afirmación no es rotunda para todo el arte abstracto. Algunas expresiones de este arte buscan con la abstracción llegar a un significado por fuera de la obra vinculado a una elevación del sujeto mediante la exaltación de su espiritualidad (expresionismo), la representación de su conciencia oculta (surrealismo) o la síntesis del objeto (cubismo).

9 «Cuando en 1913, a lo largo de mis esfuerzos desesperados por liberar al arte del lastre de la objetividad, me refugié en la forma del cuadrado y expuse una pintura que no representaba más que un cuadrado negro sobre un fondo blanco, los críticos y el público se quejaron» (Malévich, Casimir y Vladimir Maiakovski, Manifiesto del Suprematismo, en De Micheli, 2000, p. 317). 
vanguardias artísticas del siglo $\mathrm{XX}$ a los diferentes avatares de esa corriente [...]" (2005, p. 167). En efecto, los lenguajes artísticos eran para cierta zona de la vanguardia, un aspecto más a destruir para desocultar esa verdad. Es esa misma obsesión por limpiar al arte de todo lo accesorio y acceder a su realidad, la búsqueda de la pureza, que atenta contra el propio lenguaje. Ese impulso por buscar la esencia del arte no como algo elevado e inalcanzable, sino entendida como lo único concreto sobre lo que se tenía certeza, los lenguajes se desmontaron hasta sus partes más ínfimas, pero encontraron allí su propio límite. Porque, al quitar capa por capa, se desmonta el dispositivo por el cual el arte revela su verdad ${ }^{10}$ y encontraron en la pureza de la inobjetividad la frontera de lo que puede considerarse artístico. Entonces, el arte decidió adosarse una función.

\section{La vanguardia como punto de partida}

La formación artística e intelectual de los hermanos Maldonado Bayley, se dio bajo ese «signo de Kandinsky», una vez producido el quiebre epistémico de las vanguardias (Foucault, 2012). A pesar de la distancia y de la voluntad de enrolarse en una genealogía latinoamericana, que se demuestra en la elección de Joaquín Torres García y Vicente Huidobro como precursores, la influencia europea fue importante, producto de la inmigración hacia Argentina desde ese continente que traía las producciones culturales, pero también porque ellos mismos eran hijos de inmigrantes y se sentían descendientes de corrientes universales. Asimilaron las ideas de la vertiente rusa y constructivista una vez clausurada la época de la primera oleada vanguardista, lo que implicó que no siempre lo hicieran de forma ordenada, a medida que se producían las experimentaciones. Además, les llegaron a través de reformulaciones y síntesis posteriores como la Bauhaus y el arte concreto.

El rechazo de la representación y la voluntad de entablar una nueva relación del arte con lo real, fueron los puntos de partida que compartieron los hermanos, como consecuencia de su formación artística e intelectual en una discursividad vanguardista ya madura. Tempranamente, en a revista Arturo (1944), Bayley ensayaba una sistematización del problema para sus coetáneos:
La preocupación por una significación exterior a la imagen existió en todas las épocas de la historia del arte. Es decir, que la imagen nacía como signo de una realidad personal, natural, conceptual, etc., pero nunca como una realidad independiente y autónoma, como una verdadera vivencia. La obra de arte nacía como una re-presentación [...]. Pero nunca una obra ha valido por su capacidad de acuerdo con una realidad cualquiera, exterior a ella, sino por su capacidad de novedad, novedad, vale decir, desplazamiento de valores de sensibilidad ejercido por una imagen.

Se ve, entonces, que el valor estético no es incumbencia del acuerdo con una realidad sino de la condición de la propia imagen. [...]

La imagen-invención es intérprete de lo desconocido, acostumbra al hombre a la libertad. (pp. 7-8).

El valor de una obra radica no en el objeto que representa, sino en su capacidad de novedad, que es una particularidad de la imagen y no de sus elementos externos. Pero, la peculiar definición de novedad como «desplazamiento de valores de sensibilidad», indica que la innovación de la imagen representativa nunca puede ser radical porque se sus-

10 Podría considerarse como sintomático de este desmembramiento del arte para alcanzar la certeza de lo real, el análisis que hace Heidegger sobre el origen de la obra de arte, que equivale para el filósofo a la esencia del arte, a la verdad que pone en acto y a su vínculo con lo real. «El arte es por ahora tan sólo una palabra a la que no le corresponde nada real» (2000, p. 31), afirma como premisa para comenzar. Su especulación filosófica desmonta la idea de obra de arte como acontecer de la verdad, entendida como real: «es verdadero lo que corresponde a lo real, y real es lo que es en verdad» (p. 67). Finalmente, ejemplifica el análisis con un templo griego, que escoge porque es una obra de arte no representativa. 
tenta sobre un corrimiento, una distorsión de la capacidad de percibir y de reaccionar a esa percepción, por lo que guardaría cierto anclaje en lo conocido. La invención, en cambio, no tiene para Bayley ese anclaje en lo conocido, no está en representación de algo ni siquiera de forma distorsionada, sino que se presenta a sí misma y a su sentido, como radicalmente nuevo. Se trata de una imagen pura, sin amarres externos, diferente a la representación que, por ser repetitiva, carece de valor y "es sólo reacción [...] Toda preocupación re-presentativa, toda voluntad de convertir a la obra de arte en un intérprete de no importa qué realidad interior, de qué sutil, compleja y nueva actitud [...] falsea la imagen y la despoja de todo valor estético" (1944, p. 8).

Con la renuncia a la representación va más allá de Mallarmé y del surrealismo en la búsqueda de la pureza porque, como los poetas del futurismo ruso, propone que el lenguaje deje de simbolizar, incluso lo que está por fuera de lo consciente. Para el joven Bayley, la inclusión de elementos ajenos que supone la representación contamina la imagen puramente artística, distorsionando su belleza. Esta problematización del carácter sígnico de la imagen y la postulación de la invención como contrapartida posible también la expresa Maldonado, esta vez, en una encuesta de la revista
Contrapunto, en los términos que le ofrecía el arte concreto:

El arte concreto no abstrae, sino inventa nuevas realidades. Es el único arte realista, pues es eminentemente presentativo. Presentar es lo contrario de representar. Un objeto representado gráficamente sobre un plano es una ilusión que niega -ópticamente- la realidad material del plano, su bidimensionalidad, su presencia. En la pintura, lo real es lo tangible, lo demás es ficción (Maldonado, 1997 [1945], p. 35).

En la última frase queda clara no solo su adhesión al arte no objetivo, sino su búsqueda de lo único que podía aseverarse como certeza en el arte, la realidad de sus premisas básicas, tangibles. Los términos que utilizan ambos hermanos son tan similares, que solo puede pensarse en una escritura colaborativa o en un intercambio fluido y una reflexión conjunta. El manifiesto invencionista, que firmaron junto a Antonio Caraduje, Simón Contreras (seud. Juan Carlos La Madid), Manuel O. Espinosa, Alfredo Hlito, Enio lommi, Obdulio Landi (seud. Rafael Lozza), Raúl Lozza, R. V. D. Lozza, Alberto Molenberg, Primaldo Mónaco, Oscar Núñez, Lidy Prati, Jorge Souza y Matilde Werbin, cuestiona también la representación. Aquí, el llamado arte abstracto se encuentra entre las manifestaciones contaminadas por elementos externos al arte, dado que presenta una imagen distorsionada de la realidad, a diferencia del arte concreto, que expone una realidad nueva:

El arte representativo muestra 'realidades' estáticas, abstractamente cristalizadas. Porque todo el arte representativo ha sido abstracto. Sólo a causa de un malentendido idealista se dio en llamar abstractas a las experiencias estéticas no representativas. En verdad, por medio de estas experiencias, conscientemente o no, se ha marchado en un sentido opuesto al de la abstracción; el resultado, que ha constituido una exaltación de los valores concretos de la pintura, lo demuestra de manera irrefutable. La batalla librada por el arte llamado abstracto es, en el fondo, la batalla por la invención concreta (AAVV, 1946, p. 8).

El fragmento explica la diferencia entre el arte abstracto y el arte concreto: mientras el primero deforma una imagen mimética, el segundo parte de los elementos de la pintura: puntos, líneas, color, leyes de la composición. Así, el manifiesto establece la diferencia de que no todo arte no representativo obedece a la premisa de no contaminación con la realidad y determina el carácter materialista de la propuesta.

Esa voluntad de entablar un vínculo directo con lo real, implicaba también romper con la 
mediación del lenguaje. Es decir, si el arte ya no representaba aquello que podía describirse lingüísticamente, ejemplificado por Foucault (2012) con el enunciado "lo que usted ve es esto" (p. 30), porque en su lugar presentaba cosas -líneas, puntos o colores, que eran objetos en sí mismos tanto para Kandinski como para los concretos-, lo que aquí se quiebra es la subordinación de la imagen a la afirmación o, lo que es lo mismo, del arte al lenguaje. En otras palabras, al descartar el arte su carácter sígnico de mediación del sentido a través de la representación, impide toda explicación discursiva. Y con la representación invalidada, ya no podía funcionar como enlace entre el código lingüístico y el visual, que quedaban disociados, de acuerdo con la ruptura epistemológica que Foucault detecta en las vanguardias.

A pesar de la similitud en los términos que utilizan Maldonado y Bayley, las consecuencias de este punto de partida eran disímiles para cada una de las disciplinas: el arte plástico se mantuvo subordinado al lenguaje hasta la ruptura epistemológica vanguardista $\mathrm{y}$, a partir del quiebre, su autonomía im- plicaba un descentramiento del lenguaje que interpeló de forma directa la poética de Bayley. Porque si Maldonado adoptó de lleno el dogma del arte concreto, ${ }^{11}$ de modo que sus exploraciones iban en la línea de los elementos estructurales de la plástica, Bayley contaba con un material bastante desacreditado para cumplir con el cometido de generar objetos poéticos que no explicaran la realidad sino que contribuyeran a conformarla, porque el lenguaje era, por definición, una mediación del sentido.

El desafío entonces era trabajar con la superficie de lenguaje, con su aspecto material, es decir, con el componente fónico y la estructura sintáctica, dejando de lado la semiosis. Al desmontar la estructura del signo y eliminar aquella que lo ligaba de forma representativa con lo real, la poesía podía emular al arte concreto. ¿Pero, cómo desplazar el sentido del signo lingüístico? ¿De qué modo podía romper su unidad? Una solución era a través de asociaciones semánticas deliberadamente imposibles, que impidieran asignar sentido a los términos. Estos dislocamientos le permitían quebrar la determinación semántica de la gramática, al tiempo que desarmaba la metáfora como unidad de sentido del poema. Así lo explicaba Juan Jacobo Bajarlía, unos años después: "La imagen, en cambio, es una dimensión emocional de la invención servida como objeto estético. Quebranta la gramática y el lenguaje lineal. Pero al quebrantar la gramática, la reelabora y la codifica dialécticamente avanzando sobre lo desconocido y maravilloso" (1964, p. 56-57).

El dislocamiento del sentido, aunque planificado, generaba un efecto muy alejado de la precisión pura de la línea que lograba Maldonado con sus composiciones geométricas. En ocasiones, breves fragmentos de discurso lógico afloran entre un volumen más extenso de sintagmas desarticulados, como si fueran una combinación posible entre otras de la masa amorfa del lenguaje. Incluso, se asemeja más a cierto automatismo controlado que practicaban los surrealistas tardíos, de quienes por esa época procuraban distinguirse:

Esto lo comprendo

No es preciso

Está bien

\footnotetext{
"Carlsund, Van Doesburg, Hélion, Tutundjian y Wantz. Nosotros declaramos: 1. El arte es universal./ 2. La obra de arte debe ser concebida y formada enteramente por el espíritu antes de su ejecución. No debe recibir nada de las formas dadas de la naturaleza, ni de la sensualidad, ni de la sentimentalidad. Queremos excluir el lirismo, el dramatismo, el simbolismo, etc./ 3. El cuadro debe ser construido enteramente con los elementos puramente plásticos, es decir, planos y colores. Un elemento pictórico no tiene ninguna otra significación más que la de «sí mismo»; como consecuencia el cuadro no tiene ninguna otra significación más que la de «sí misma»./ 4. La construcción del cuadro, así como la de sus elementos, debe ser simple y controlable visualmente./ 5. La técnica debe ser mecánica, es decir, exacta, anti-impresionista./ 6. Esfuerzo por la claridad absoluta". En: Revista Art Concret, París, abril de 1930.
} 
Lo veo

Así que adelante acero callhermano conceptuando

La lista está completa y lancha tiniebla

No se ha visto al displicente

soldado de la cámara

No se ha visto a Marte esta mañana

El ajetreo no ha experimenta-

do los sinsabores boreales

Contrincante descansa

Con el ala chocó la mujer

Chocó con blandura untuosa y lloró

Chocaba con flor dios linterna

La linterna se apagó

No es preciso

Hoy

Hoy es preciso llevarle este bastón barroso

Barroco

Hoy discurso hoy poeta hoy un salto

Hoy yo lo comprendo bien hoyado

Yo hoyo este día con su noche incluso hasta luego

Hoyo este aparato miristicáceo

Muchas gracias se ve muy

bien dodecaedro

Si lo van a empujar sería

Una aspirina o la libertad

Libre conferva no estás en buen estado

Solsticio de verano sobre este pan huía

$\mathrm{Y}$ adentro por cuantos canales rampaba

Que bien bien bien bien

Había en la vejiga amterial de conversación

Pero el pan migraba y cuic

Hoy estreno hoy edgar

Loturcamonudolantianamente

[...]

(Bayley,1944b, p. 15).
Lejos de cualquier estética purista que abogara por la precisión de la palabra, por el vocablo exacto, los primeros poemas de Bayley generan un efecto lúdico sin ingenuidad, de humor corrosivo que toma el pelo a la lógica semántica del lenguaje. Lejos, muy lejos, de las búsquedas del menor de los Maldonado, que seguiría rascando las capas de significación del arte en busca de su verdad.

\section{Hacia la médula del arte}

Las especulaciones teóricas de Maldonado continuaron cuestionando la naturaleza ilusoria, ficticia y engañosa de la representación de un modo casi obsesivo. En primer lugar, experimentó con el recorte del marco para evitar la ilusión que supone el marco ventana y para lograr que las figuras entraran en relación con la figura del plano. Pero, al plantear que «mientras haya una figura sobre un fondo, ilusoriamente exhibida, habrá representación» (Maldonado, 1946, p. 5), los artistas concretos encontraron que esa experimentación no solucionaba el problema. Entonces, decidieron disolver el fondo y probar con la coplanariedad, es decir, la disposición de figuras separadas en el espacio en un mismo plano pero sin fondo, que generaran una valoración tensional a un mismo nivel (García, 2011; Lauria, 2003). El experimento tampoco satisfaría al artista: "La oposición entre figura y fondo seguía existiendo, pero de ilusoria que era antes había pasado a ser concreta" (Maldonado, 2003 [1948], p. 11), decía refiriéndose al plano de apoyo de las figuras, ya fuera un rectángulo de madera o la pared.

La exigencia por abolir la ilusión del arte, se había convertido en una preocupación obstinada. Nada era suficiente para Maldonado: poco tiempo después de experimentar con la coplanariedad, volvió a las formas geométricas sobre un plano cuadrangular y el problema se volvió una aporía. Cualquier intento por evadir la representación lo devolvía al punto de partida:

El intento suprematista o de la 'concentración temática' -es decir, dar toda la importancia a la anécdota plástica $\mathrm{y}$ usar el fondo simplemente como soporte, sin ninguna participación en la estructura- era inaceptable porque se oponía a uno de los principios fundamentales del concretismo: exaltación de los elementos materiales concretos de la pintura, exaltación del plano-superficie como elemento plástico, planismo [...].

[...] el intento neoplasticista o de la valorización del fondo por medio de complicaciones lineales $[\ldots]$ es una solución ficticia porque no ha sido lograda a través de una admisión del problema, sino de una escapatoria. [...] había que buscar la salida por 
el lado del a valorización del fondo en un sentido de plástica absoluta. Había que traer el fondo al mismo nivel óptico que la figura pero no por medio de una valorización lineal (neo-plasticismo), sino tensional entre las figuras [coplanariedad]. [...] Sin embargo, los resultados en general son objetables. [...] Vantongerloo y Bill han sugerido que quizás la ruta sea superar las figuras limitadas. Liquidar las figuras, en una palabra, y hacer (por medio de sutiles elementos no figurales) vibrar al máximo el fondo, sería uno de los modos. El otro consistiría en diluir el perímetro de las figuras [...]. La dilución perimetral es lisa y llanamente un regreso al 'sfumato' representativo.

[...] la búsqueda de lo ilimitado dentro de una forma limitada $[\ldots]$ crea una situación representativa [...] (Maldonado, 2003 [1948], pp. 12-14).

La cuestión del plano como fondo parecía no tener escapatoria. Una y otra vez repasaba las soluciones alcanzadas por los distintos movimientos de arte abstracto, pero no encontraba una respuesta que descubriera la pureza de lo real. Tampoco la hallaba él mismo sin atentar contra la condición de arte. Maldonado redactó este tratado sobre el arte concreto en Zúrich, en 1948. Durante su viaje a Suiza e Italia, se contactó con concretos -Max Bill, Camille Graeser, Max Huber, Richard Paul Lohse, Verena Loewensberg y el resto del grupo Allianz, y con los italianos Bruno Munari, Piero Dorazio, Gillo Dorfles y Gianni Dova, entre otros (Lucena, 2015; Méndez Mosquera y García, 2007)-, así como con constructivistas -Vantongerloo, Vordemberge-Gildewart, etc. (García, 2011)-. Gracias a ellos, se informó de las ultimísimas tendencias en las que trabajaban, que incluían las ideas sobre diseño y tipografía (Méndez Mosquera y García, 2007).

Bayley, mientras tanto, distendía un poco la cuestión teórica y rescataba de la poesía su capacidad de resistencia, su misión inconformista, su función política de rechazar los sentidos dados peligrosamente confortables. En un bello texto de tono bélico publicado en la primera plana del número 1 de la revista Contemporánea, el poeta llama a plegarse a esa resistencia pacífica, a no claudicar:

La poesía es invadida por momentos. [...] La invasión dura todavía, pero la resistencia existe, no lo dudemos. Esa resistencia está en las calles, a horas determinadas. En las conversaciones fervorosas, en el cielo de cada mano. Es una resistencia extensa y secreta que da su golpe en el lugar menos esperado. Y a cada instante hay nuevos reclutas y se consiguen nuevas armas. [...] Las deserciones no desmoralizan sus esfuerzos. En lucha abierta o secreta, la poesía mantiene su combate contra las curvas untuosas de la adaptación. Allá, en el resultado, más allá todavía, en las honduras de la claridad, todas las sonrisas de las multitudes, de los niños, de los jóvenes amantes, de los fusilados, siguen alimentando su reto cotidiano, su familiaridad con lo desconocido.

[...] Están los que temen, los que dudan en el momento decisivo, pero también están los otros, los que en la cresta de la batalla mantienen su hambre encendida, los que no dilapidan [...]. Están los ojos puros en que amanecen los años, la alegría, el porvenir luciente; está, y es lo más peligroso para vosotros, la muerte, segura de su fecundidad. [...]

La poesía es un reto cotidiano. $[\ldots]$

[...] Aquellos a los que les faltó el coraje o la justicia, y abandonaron, tienen reemplazantes en el torbellino magnífico de nuestras mañanas reguladoras.

Su victoria es vertical, y será la existencia (Bayley, 1948, p. 1).

Persiste el tono combativo de los primeros textos, pero en lugar de ir contra la representación, deja que ingresen los elementos ajenos a la poesía como armas necesarias para resistir el conformismo y los sentidos dados e impuestos. Esa resistencia se da en la experiencia colectiva de las calles y en la individual de cada mano, en el sacrificio que fecunda hacia el porvenir. La diferencia, no solo de estilo sino de preocupaciones, era 
ahora grande con su hermano: mientras uno continuaba buscando la médula del arte seccionando sus partes, el otro advertía que esa esencia no está en el centro vacío de los materiales, sino afuera, en la sagrada cotidianeidad de la vida. Evidentemente, Bayley ya había notado la esterilidad del dogma, el callejón sin salida que suponía para su poética prescindir de la lógica del lenguaje, de los sentidos que vertían esa vida sobre las palabras.

La revista donde salió ese texto era la nueva iniciativa de Juan Jacobo Bajarlía. A diferencia de las publicaciones de la Asociación Arte Concreto-Invención, tenía un espíritu más abierto, capaz de congregar movimientos de propuestas completamente opuestas, como el surrealismo y el arte concreto, y buscaba difundir las tendencias renovadoras más recientes. Bajarlía venía apoyando este tipo de tendencias desde antes del invencionismo y esta postura menos dogmática pudo haber influenciado a Bayley en la convicción de que la contienda era contra las formas perimidas, a favor de instalar las tendencias modernas o, como expresa el subtítulo de Contemporánea, por «la revolución en el arte».
Maldonado volvió de Europa en junio de 1948, algo más de un mes antes de que se publicara Contemporánea. La revista informa sobre su buena recepción en Milán. Allí se contactó con el PC italiano y sus debates que, junto con los aspectos elaborados por el grupo suizo Allianz, convencieron al artista de la necesidad de relajar los dogmas estéticos y políticos, y de generar una apertura crítica (Lucena, 2015), que le permitiera pensar problemas más acuciantes para la sociedad, en lugar de cuestiones puramente estilísticas. A partir de allí, comenzaría a pensar el concretismo como un método más que un fin en sí mismo y a plantearse la pregunta por la función social del arte. Sus pinturas, sin embargo, no perderían la nitidez que habían alcanzado en la búsqueda de su esencia.

\section{En busca de la contaminación}

Probablemente, el relajamiento de los dogmas y la apertura a luchar por la instalación del arte moderno, más que contra la representación, fue la trastienda para que los hermanos Maldonado Bayley se vincularan con el proyecto de la cofradía surrealista de Aldo Pellegrini, Elías Pitterbag y Enrique Pichón-Rivière: la revista Ciclo (1948-1949). Allí, Maldonado aplicó por primera vez los tipos traídos de Europa y creó un diseño completamente nuevo para una revista porteña. ${ }^{12}$ Pero únicamente una ojeada distraída puede afirmar que se trataba de una revista surrealista, cuando hay tanto Breton, Lautréamont y Char como Mondrian, Moholy-Nagy y Bill. La impronta de los hermanos era patente.

Además de los tipos sans serif, Maldonado había traído de Europa la inquietud por la función, pregunta que se respondía con más facilidad a través de las artes proyectuales: diseño gráfico, tipografía, diseño industrial y arquitectura obedecían claramente al para qué artístico y permitían introducir su praxis en la vida cotidiana, la premisa que desvelaba desde siempre a las vanguardias. El diseño y la planificación de objetos de uso, espacios para habitar y plataformas gráficas, eran abordadas como una versión moderna de las artes aplicadas, ahora reivindicadas como prácticas artísticas genuinas, al mismo nivel que las bellas artes:

[...] a nadie debe sorprender que, síntesis del mejor arte y de la mejor ciencia, el diseño sea capaz, sin abandonar su propio territorio, de suscitar interacciones más funcionales, esto es, más directas,

12 Carlos Méndez Mosquera, diseñador gráfico discípulo y compañero de Tomás Maldonado en axis, el primer estudio de diseño del país, afirma que la tipografía utilizada para la revista Ciclo fue la Spartan. En el Boletín del CEA 2, la segunda publicación diseñada por Maldonado (1997), dice que usó «la misma "helvetica-groteske-spartan"» de Ciclo (p. 17). Se trata de tipografías de diferente origen, pero todas similares y sin palo. La Spartan deriva de la Futura, el prototipo de tipografía geométrica sans serif del siglo XX, que fue desarrollada por Paul Renner en 1927 con base en figuras geométricas. 
menos mistificadas, entre la realidad psicobiológica del hombre y su medio.

[...] el diseño se presenta hoy como la única posibilidad de resolver, sobre un plano efectivo, el problema más dramático y agudo del espíritu de nuestro tiempo, o sea, la situación de divorcio existente entre el arte y la vida, entre los artistas y los demás hombres. Las causas de este divorcio son muchas y complejas, y no es este el lugar de analizarlas, pero no hay duda de que es al mito de «lo artístico» al que debemos atribuir no pocas de las responsabilidades psicológicas de este conflicto. «Lo artístico», en efecto, se presenta hoy como el germen más profundamente desocializador de la cultura contemporánea, como la modalidad más enfermiza del individualismo y del aristocratismo intelectual (Maldonado, 1949, p. 7; énfasis en el original).

Su interés por la función del arte tenía varias causas, pero una sola raíz. El objetivo de religar el arte con la praxis vital seguía vigente para los concretos y la búsqueda de la esencia artística respondía a esa intención. Ponerse en contacto con lo más puro del arte, con su verdad, significaba plantear interacciones más genuinas y directas con lo real, lo que redundaría en la religación de las prácticas. Pero como se ha analizado, el resul- tado de esas búsquedas no fue satisfactorio y se convirtió en una aporía. Por otra parte, Maldonado estrechó relaciones con Max Bill, un artista concreto suizo que se desarrollaba de manera pareja en pintura, escultura, arquitectura y diseño. Discípulo de Kandinsky y Klee, había estudiado en la Bauhaus de Dessau, mítico punto de encuentro de vanguardistas, y conservaba su impronta interdisciplinaria y exploratoria, así como la importancia ecuánime a la maestría en el trabajo técnico y a los aspectos estéticos y creativos, para dar forma a la nueva belleza que la producción en serie aportaba a una vida cotidiana alejada del arte.

La coincidencia del estancamiento de sus indagaciones con la perspectiva de Bill y del resto de los concretos, lo llevó a encontrar en la función el elemento de articulación que colocaba al arte en el flujo de la vida diaria. Los modos de producción se habían democratizado y habían logrado que más y más gente accediera a bienes de uso; del mismo modo, se debía dejar atrás el concepto aristocratizante de «lo artístico» como elemento superior e inefable, para alcanzar a más gente. El diseño era una respuesta posible porque a través de la producción en serie era capaz de aportar belleza, una nueva belleza, ${ }^{13}$ a la vida cotidiana de miles de millones de personas. Tal como expone en el fragmento recién citado, Maldonado había comprendido que buscar la esencia del arte no hacía más que aislarlo cada vez más, porque si el problema se había convertido en una aporía, la pureza artística era inefable y, por eso, contribuía a acrecentar ese mito de «lo artístico» que aislaba al arte de la vida corriente. Para restituirlo, era preciso vincularlo con lo útil:

[...] esta función social del diseño está vinculada, por cierto, al resto de las manifestaciones artísticas, pero no depende totalmente de ellas; no es, como la idea corriente lo supone, una manifestación aplicada, menor, en última instancia infrartística, de determinados principios estilísticos de un arte jerárquicamente superior. Este malentendido, este persistente equívoco, que gusta establecer jerarquías en la creación de las formas [...], este fetichismo de «lo artístico» debe ser superado por todo aquel que aspire a aprehender el sentido último de la nueva visión (Maldonado, 1949, p. 7; énfasis en el orginal).

Aunque perdiera su pureza, no significaba rebajarlo, sino que se elevaba la labor artesanal del arte y así jerarquizaba todas sus facetas. Como explica Jacques Rancière al analizar la tradición

13 La cuestión de la nueva belleza que plantea la producción en relación con el diseño industrial se analiza en «Marxistas, ma non troppo. El derrotero de las ideas de izquierda en el proyecto Nueva Visión», en prensa. 
que problematiza la distinción entre bellas artes y artes aplicadas, desde Arts \& Crafts a la Bauhaus, en esta falsa división radicaría el problema de la separación del arte y la vida, como bien sabía Maldonado (2013):

La distinción entre las bellas artes y las artes aplicadas institucionalizó en las costumbres y las mentes esa separación entre el trabajo del artista y el del artesano. Esta tiene su expresión en el culto del arte puro cuyo ídolo es la obra de arte «portátil», la pintura de caballete hecha para el goce de los salones y los museos. A la inversa, el único verdadero arte es el presuntamente aplicado, el que se aplica a la construcción y la decoración de los edificios, el arte que sirve a la vida, que sirve para darle abrigo y expresarla. Abrigar y expresar: la conjunción de estas dos funciones es esencial porque permite recusar la oposición demasiado simple entre el objeto de utilidad y el objeto de contemplación desinteresada. La oposición convencional de lo útil y lo bello deshace la unidad del arte y consagra la división del trabajo y la jerarquía de las vidas (p. 165).

La poesía tenía más dificultades para hallar su función. La búsqueda de la pureza también la había conducido a una zona estéril, pero las indagaciones de Bayley no fueron tan obstinadas. Como se ha visto, el poeta advirtió rápidamente el callejón sin salida al que conducía desarmar el signo lingüístico y violentar la lógica del lenguaje. Por eso, había propuesto resistir los sentidos dados, el inconformismo, como el cometido fundamental de la poesía. Devolverle una función era colocarla nuevamente en el flujo vital, pero esa función no podía homologarse a la utilidad de los objetos de diseño, aunque el concepto interpelara su reflexión teórica.

Ya en la revista Arte Concreto Invención, expresaba que "hay un desarrollo histórico de las formas poéticas, que podemos explicar con respecto a los cambios sociales y económicos, pero hay también una función de la poesía, que se ha ejercido a través de los más diversos estilos creadores, y cuyo carácter interesa definir" (1946: 13). Esta noción continuaría desarrollándose en "Realidad interna y función de la poesía". Desde el título del ensayo, Bayley expresaba lo que había desvelado a los hermanos: lo real intrínseco del poema, su esencia material pura, junto con la función, el nuevo aspecto que conectaba el arte con la vida:

[...] existe una condición permanente de la poesía que se desdobla en dos aspectos: uno de ellos se refiere a las características esenciales de la realidad poética, es decir, a todo aquello que la poesía ha tenido siempre, aquello que ha estado presente de algún modo, en una serie cual- quiera de versos, de auténtico valor poético; y el otro se relaciona con la función que la poesía ha venido cumpliendo, o sea con la capacidad de la poesía para satisfacer, a través de la sensibilidad, ciertas necesidades humanas (Bayley, 1952, p. 4; énfasis en el original).

En el mismo artículo aclara que, por «realidad interna», no entiende la experiencia emocional del poeta, que no desconoce, sino que radica en la valencia poética de las palabras, la elección de los términos justos que hace el poeta y que están cargados de un valor subjetivo, de un tono -distinto de su sentido-que se mantiene igual para todos. Se trata del lenguaje poético, en el que "la palabra entra en relaciones que, en vez de reducir o encerrar su poder poético, como en el discurso lógico, tienden a liberarlo, dotándolo de una coherencia nueva, inventiva". De modo que, es la "liberación creadora de la energía emocional de las palabras, donde parece residir el proceso interno de la poesía" (p. 4). Luego, define la función poética como un modo de relacionarse con el mundo circundante:

[...] la poesía ha servido para que el hombre mantuviera tensa una disposición de su espíritu, sin la cual no hubiera podido construir el mundo que le rodea, edificándose, por añadidura a sí mismo. $\mathrm{O}$, como dice Reverdy, sin la actividad poética, que él defi- 
ne como el acto de transmutación de lo real exterior en lo real interior, el hombre no hubiese podido superar nunca el obstáculo inconcebible que la naturaleza levantaba frente a él (p. 4).

De modo que, la función de la poesía es la de una mediación cognoscitiva, un modo de conocer y abarcar el mundo exterior, que mantiene al hombre alerta. Bayley vuelve a reconocer y a valorar la función mediadora del lenguaje entre el individuo y lo real circundante. Aunque, la noción de «realidad poética» quedaba en este ensayo bastante delineada como esa parte esencial que define lo poético, es decir, el lenguaje poético, la función no quedaba delimitada. Pero, resulta interesante que, según la describe, esta función cognoscitiva no tiene un carácter excepcional, no pertenece a cierta clase de individuos iluminados, sino que es una disposición que existe en todas las personas, lo que contribuiría a encaminar la noción.

Esta concepción más orgánica de lo poético, centrada en su elemento permanente, exhibe un eco de la idea de gute Form [buena forma] de Max Bill, que establecía la armonización de la tecnología de producción y la funcionalidad de un objeto (Crispiani, 2001). Esto se advierte cuando describe el estilo poético como "resultante de un encuentro o conjugación crítica, entre esa vocación de enriquecimiento y plenitud vital y las condiciones objetivas de los recursos de expresión" (Bayley, 1952, p. 3). El enriquecimiento y la plenitud de la vida son identificados unas líneas más adelante como la función, y las condiciones objetivas de los recursos expresivos implican los materiales y la técnica de la composición poética. En el estilo, es decir, la forma, confluyen función y condiciones objetivas de producción, influencia de Bill y persistencia de sus ideas de juventud.

Una vez atravesada la experimentación geométrica, la aporía teórica a la que había llegado y la incorporación de la función como un elemento central que vincula el arte con la vida, la noción de pureza se transformaría también para Maldonado. En un artículo del número 2-3 de la revista nueva visión que dirigía, el artista pone en discusión la noción a partir del análisis de la obra de Friedrich Vordemberge-Gildewart, que se había iniciado directamente en las formas abstractas, en lugar de partir de la figuración. Se pregunta allí si «la pureza artística sería entonces una categoría sólo alcanzada por los artistas concretos de orientación constructiva, sólo por aquellos que - con Mondrian- juzgan que "la plástica exacta requiere de medios exactos", por lo que propone analizar "qué hay de cierto en la pureza que se le atribuye [a Vordemberge-Gildewart]. A él y al arte concreto" (Maldonado, 1953, p. 12).

\begin{abstract}
Establece entonces que «si por pureza se entiende -éste es para mí el único sentido admisible - la exacta coherencia entre los propósitos inventivos de una obra y los medios elegidos para su objetivación, o sea, entre la función y la forma, toda obra verdaderamente lograda sería, por lo tanto, pura» (p. 13), por lo que la gute Form billiana, que busca armonizar función y forma, es para el artista sinónimo de pureza en el arte. Analiza cómo la noción de «pureza artística» corriente es vaga, aplicable a cualquier forma eficientemente inventada, y cuya indeterminación contribuye a fomentar la jerarquía de «lo artístico». Por eso, rescata de la obra de Vordemberge-Gildewart «su contaminación. Porque la obra de arte -lo queramos o no- está siempre contaminada. El artista, el gran artista, es el hombre más contaminado por los virus morales y sociales más filtrables de cada época» (p. 14).
\end{abstract}

El número 2-3 de Nueva visión había salido algo atrasado luego del primero que había visto la luz en 1951. Resulta evidente la simultaneidad con la reflexión de su hermano, que por la misma época estaba pensando en una función poética en contacto con la realidad exterior. Ambos estaban reconociendo la necesidad de que el arte, incluso en 
sus formas más planificadas y menos intuitivas, estuviera plenamente vinculado a su aquí y ahora. Pero, Bayley introduce una cuestión que no está presente en las teorías billianas ni en otras teorías alemanas que definieron la gute form, tampoco en las exposiciones de su hermano: función poética y condiciones de producción y materiales no conviven de forma armónica, sino que establecen una tensión crítica, que en definitiva constituye tanto la novedad del estilo como el impulso de las tendencias artísticas hacia su transformación.

\section{Aire de familia}

En una entrevista personal realizada en Milán a fines de marzo de 2014, Maldonado recordaba una semblanza inédita sobre su hermano, donde identificaba su estilo poético con la rama materna de la familia, de donde el poeta adoptó su nom de plume. Procedentes de Dublín y católicos practicantes, los Bayley eran extravagantes, orgullosos de su diferencia, de ser «poco ingleses». Se trataba de gente auténticamente no conformista, a diferencia de la rama paterna, de origen criollo, que ejercía el tipo de calma que brinda seguridad. Pero el carácter irlandés que le suscribe a su hermano no estaría únicamente en su personalidad irreverente $\mathrm{o}$ en el humor corrosivo que caracterizaba tanto su temperamento como las historias del Doctor Pi
(Bayley, 1999 [1987]), sino fundamentalmente en un rasgo que habría dado forma a su poética. Una profunda aversión por toda forma de sentimentalismo, por la sensiblería exagerada, por la hipocresía emotiva, es para el artista una característica de la poesía de su hermano de raíz irlandesa, que puede rastrearse en la tradición literaria de ese país, en Oscar Wilde, William B. Yeats, James Joyce, etc.

La operación tiene múltiples sentidos, algunos más calculados que otros. Los colegas de Bayley no lo interpretaron favorablemente porque esa filiación implicaba retirarlo de la serie de la poesía argentina. Pero, no era ese el espíritu del ejercicio interpretativo. Por un lado, el diseñador pretendió tener un gesto de generosidad artística, al colocar a su hermano en una estirpe de reconocidos e influyentes escritores occidentales; por otro, el argumento le sirve para tomar distancia de una parte de su linaje que prefiere domesticar, reconociéndose más parecido a sus ancestros criollos por la racionalidad de sus intereses y su postura anti-bohemia. Sin embargo, esa aversión por la carga emotiva y la intención de dejar fuera cualquier expresión personal, aunque es menos evidente en sus inicios de la revista Arturo (1944), resulta clara tanto en el derrotero de su hermano como en el suyo propio.
La propuesta inicial de crear objetos plásticos no representativos, de terminar con la representación y afirmar la autonomía del arte, prescindía de la individualidad del artista $y$, por lo tanto, de su emotividad, para afirmar la universalidad en figuras inteligibles por toda la humanidad. Más adelante, la búsqueda de la función a través de las artes proyectuales estaba en la antípodas de ese sentimentalismo inútil, cuyo desprecio adjudicaba a la rama familiar irlandesa. Incluso, cuando advierte la necesidad de un arte contaminado, de un artista involucrado en la coyuntura, cuestiona la afirmación de Theo van Doesburg, uno de los fundadores del concretismo, de que la plástica proviene del interior del artista, porque lo considera un rasgo romántico y solicita una revisión de ese aspecto (Maldonado, 1953).

Pero, como ha demostrado el análisis comparativo entre las poéticas, más que una determinación del ADN, esta coincidencia en el rechazo del sentimentalismo y en una estética de formas puras, se daba por las búsquedas compartidas, la reflexión conjunta, las influencias mutuas de dos hermanos que compartían vida, intereses $\mathrm{y}$, fundamentalmente, una marcada afición por la intelectualidad aplicada al arte. A mediados de los años cincuenta, sus actividades se encontraban distanciadas, incluso geográfica- 
mente: Bayley tenía una activa participación en el grupo editor de la revista poesía buenos aires (1950-1960); y Maldonado, desde 1954, estaba abocado al desarrollo profesional del diseño en Alemania, al tiempo que hacía sus primeras experiencias como docente en la Hochschule für Gestaltung (HfG) [Escuela Superior de Estudios sobre la Forma] de Ulm. A pesar de la distancia geográfica y de la que marcaban las disciplinas, una vez más, las preocupaciones confluían.

En 1953, Maldonado había publicado un artículo en el n. ${ }^{\circ} 4$ de nueva visión, titulado «Problemas actuales de la comunicación». Allí, destacaba el lugar central de la comunicación en la cultura humana, porque es un instrumento "de individuos sociales en menester cotidiano. [...] La verdadera comunicación sólo puede cumplirse en la órbita del mundo común, cuyo fundamento es [...] la vigilia, es decir, la atención desvelada sobre lo cotidiano" (p. 21). Y luego, la destaca como

el tema central de los que tienen la responsabilidad de elaborar, inventar o poner en circulación los signos o símbolos que la hacen posible; tanto a los que han planteado su tarea en términos «indirectos», a través de los géneros tradicionales de la expresión -pintura, escultura, arquitectura, poesía, música- cuanto a los que han preferido los términos «directos», a través de los procedimientos de alcance multitudinario -artes gráficas, cine, televisión, fotografía, radio. [...] Las diferentes respuestas que ellos consigan dar a estas preguntas han de caracterizar y definir el sentido social de sus respectivas obras. De ahí que, en alguna medida, siempre tengan conciencia (buena o mala) de estar operando en el punto neurálgico de la sociedad en que viven. (p. 24).

Estas ideas influenciaron no solo a Bayley, sino también a sus colegas. A partir de 1954, se advierte en poesía Buenos Aires una intención de devolver al poema la semiosis, de relajar el hermetismo para restablecer una función comunicativa en la poesía que contribuyera a una comunión de individuos, poetas y lectores. Incluso, Raúl Gustavo Aguirre comenta el artículo de Maldonado y reflexiona sobre el problema en "Notas sobre el problema de la comunicación" (1953-1954). Evidentemente, la poesía había encontrado su función. Era ahora un instrumento vivo para superar el aislamiento, pero también para resistir la dominación, como ya advertía Bayley en 1948. En "El arte, fundamento de la libertad" (1955), analiza la obturación de la comunicación en el contexto de la cultura burguesa y el surgimiento de la cultura de masas, para reafirmar el papel del arte: "El arte tiende, en efecto, a crear y desarrollar entre los hombres relaciones de comunión por medio de la actividad subjetiva de cada uno" (p. 8).

El tema sería central en las conferencias de la Primera Reunión de Arte Contemporáneo en Santa Fe, organizada por Francisco Urondo, que estaba a cargo de la sección Arte Contemporáneo del Instituto Social de la Universidad Nacional del Litoral. La conferencia de Bayley se titula, como una respuesta a su ensayo anterior, "En torno a la poesía contemporánea: la poesía como realidad y comunicación". Analiza la situación de la poesía como un tipo de conocimiento del mundo activo, experiencial, no reflejo sino creador de sentido que, en tanto constituye la realidad, la ensancha y la transforma. Es la fuerza subjetiva que desata, unida a una conciencia poética extendida, la que pone en funcionamiento ese conocimiento que, si logra ser difundido a otros, se produce la comunicación, que entiende como una solidaridad efectiva entre hermanos, como una soledad compartida, que se coloca al hombre en la posición de modificar su mundo. Aquí, convergen muchas de sus ideas de años anteriores: la poesía como un objeto real y no reflejo que incide la realidad, como forma de conocimiento, como fuerza subjetiva, como proceso de jerarquización humana $\mathrm{y}$, ahora, como función comunicativa. 
Aunque Maldonado afirmara en su artículo sobre Vordemberge-Gildewart, que la pureza en el arte era una fábula que había caducado, el camino recorrido por los dos hermanos hacia la esencia del arte y su culminación en la búsqueda de una función, los condujo, justamente, a una estética sobria, de líneas simples, cuya característica más evidente es la pureza de su forma y la utilización de los elementos exactos para alcanzarla. Un devenir pureza, una pureza como efecto de sentido ha sido el punto de llegada de dos poéticas surgidas en el momento de mayor madurez vanguardista, bajo el signo de lo que concibió Kandinsky. Como expresó Bonsiepe de frente a un juego de tazas diseñado por Maldonado, no puede afirmarse otra cosa de sus diseños para Olivetti. Tampoco cabe otra descripción para la poética ya madura de Bayley, que de allí en más escribió con la exactitud de un cuadro concreto:

Me ha tentado siempre la claridad

Y la claridad se me ha negado a veces
Como un pájaro que vuela en sueños

$\mathrm{Y}$ cae y sigue cayendo

Sin volar

Como peso muerto

Me ha tentado siempre la claridad

Especialmente la claridad de las hojas de sáuco

También la claridad del guijarro

$\mathrm{Y}$ de las ramas de abeto

Y la rápida y voraz claridad de una salamandra

He querido tener claridad para mirar

Los terrones del campo recién movido

Y para mirar también el mismo arado

Y el agua que se desliza límpida por la acequia

Claridad he querido para recorrer tantos sueños

Y glorias y poderes y dispersas situaciones y gentes

Y para estar en el aire sin ausentarme del fuego

Me ha tentado siempre la claridad

De estar totalmente en cada flor

En cada herida o condena o semilla

He querido tener claridad para vivir
Y cuando al fin pude definir la claridad que yo buscaba Advertí cuánto sueño y plumón y roja tierra Y confusión y olvido hacen falta para comprender claramente

Y estar aquí con total lucidez sentado a la vera del camino Avivando el fuego bajo el cielo y el polvo de las horas

Y como me ha tentado siempre la claridad

Aquella vez cuando bajo un abierto y extendido sol

Comenzaron a encresparse las aguas de la bahía

Hasta adquirir un tinte violáceo

$\mathrm{Y}$ un gran pájaro blanco surgió de repente de entre las nubes

Batiendo sus alas y revoloteando suavemente a mi alrededor

Decidí que era el momento de arrojar estas palabras al mar

Porque la claridad que tanto he buscado

Sólo está en algunos silencios

En algunos espacios en blanco

Antes y después de unas pocas y triviales palabras. 


\section{Referencias}

Aguirre, Raúl Gustavo. primavera de 1953 - verano de 1954. «Notas sobre el problema de la comunicación». poesía Buenos Aires (13-14), 17.

Arturo. Verano de 1944. (1).

AAVV. (1946). Manifiesto invencionista. Revista Arte Concreto Invención (1), 8.

Badiou, A. (2005). El siglo. Buenos Aires: Manantial.

Bajarlía, J. J. (1964). La polémica Reverdy-Huidobro. Origen de Ultraísmo. Buenos Aires: Devenir.

Bayley, E. (1999 [1983]). Vida y memorias del doctor Pi. En Obra completa (pp. 451-508). Buenos Aires: Grijalbo Mondadori.

Bayley, E. (1957). En torno a la poesía contemporánea: la poesía como realidad y comunicación. En AAVV, Primera reunión de arte contemporáneo (pp. 112-120). Santa Fe: Universidad Nacional de Litoral - Instituto Social.

Bayley, E. (1955). El arte, fundamento de la libertad. Poesía Buenos Aires, (18), 5-8.

Bayley, E. (1952). Realidad interna y función de la poesía. Poesía Buenos Aires, (6) (7), 3-4 / 7-12.

Bayley, E. (1948). La poesía. Contemporánea, año1(1), 1.

Bayley, E. (1946). Sobre la invención poética. Revista Arte Concreto Invención (1), 13.

Bayley, E. (1944a). Sin título. Arturo, (1), 7-8.

Bayley, E. (1944b). Estreno escurre. Arturo, (1), 15-16.

Bejarano, A. (julio-diciembre de 2016). Poéticas del intruso. Jacques Rancière, lector de Mallarmé. La Palabra, (29), 129-137.

Crispiani, A. (2001). Un mundo continuo. ARQ (Santiago), (49), 57-59.

De Micheli, M. (2000). Las vanguardias artísticas del siglo XX. Madrid: Alianza.

Foucault, M. (2012). Esto no es una pipa. Ensayo sobre Magritte. Buenos Aires: Eterna Cadencia.

Foucault, M. (2002). Las palabras y las cosas. Una arqueología de las ciencias humanas. Buenos Aires: Siglo XXI. 
García, M. A. (2011). El arte abstracto. Buenos Aires: Siglo XXI.

Hauser, A. (1964). Historia social de la literatura y el arte (vol. 2). Madrid: Ediciones Guadamarra.

Heidegger, M. (2000). El origen de la obra de arte. En: Arte y poesía (pp. 29-100). Buenos Aires: Fondo de Cultura Económica.

Lauria, A. (2003). El arte concreto en Argentina. Buenos Aires: Centro Virtual de Arte Argentino - Gobierno de la Ciudad de Buenos Aires. Recuperado el 5 de febrero de 2018, de http://cvaa.com. ar/02dossiers/concretos/03_definicion.php.

Lucena, D. (2015). Contaminación artística. Vanguardia concreta, comunismo y peronismo en los años 40. Buenos Aires: Biblos.

Maldonado, T. (1953a). Problemas actuales de la comunicación. Nueva visión, (4), 21-25.

Maldonado, T. (1953b). Vordemberge-Gildewart y el tema de la pureza. Nueva visión, (2-3), 12-18.

Maldonado, T. (1949). El diseño y la vida social. Boletín 2 del Centro de Estudiantes de Arquitectura (2), 7-8.

Maldonado, T. (2003). El arte concreto y el tema de lo ilimitado. Notas para un estudio teórico. Zurich 1948. Buenos Aires: Ramona.

Maldonado, T. (1946). Lo abstracto y lo concreto en el arte moderno. Revista Arte Concreto Invención (1), 5-7.

Maldonado, T. (1945). «Encuesta». Contrapunto. Año 1 (3) en: Maldonado, Tomás. 1997. Escritos preulmianos. Buenos Aires: Infinito, 35-36.

Méndez Mosquera, C. A., \& García, M. A. (2007). Notas sobre la revista nueva visión y sus recorridos. En: Tomás Maldonado, un itinerario (pp. 178-189). Buenos Aires: Museo Nacional de Bellas Artes.

Poggioli, R. (1964). Teoría del arte de vanguardia. Madrid: Revista de Occidente.

Rancière, J. (2013). El arte decorativo como arte social: el templo, la casa, la fábrica. París, Londres, Berlín. En: Aisthesis. Escenas del régimen estético del arte (pp. 159-181). Buenos Aires: Manantial. 